\title{
Millimeter-wave Measurement of Frozen Hydrometeors during the 2003 Wakasa Bay Field Experiment
}

\author{
${ }^{1}$ Min-Jeong Kim , ${ }^{2}$ D.-E. Chang, ${ }^{1}$ J A. Weinman, ${ }^{3}$ J. R. Wang, ${ }^{4}$ S. Tanelli, ${ }^{5}$ J. I. Roman-Nieves, and ${ }^{5}$ S. M. Sekelsky \\ 1. Department of Atmospheric Sciences \\ University of Washington, Seattle, WA 98195 \\ Phone: 206-685-1851, mikim@atmos.washington.edu \\ 2. Forecast Research Laboratory, \\ Meteorological Research Institute, Seoul, 156-720, Korea \\ 4. Atmospheric Radar Science and Engineering group \\ Jet Propulsion Laboratory, California Institute of \\ Technology, Pasadena, CA 91109 \\ 5. Department of Electrical and Computer Engineering \\ University of Massachusetts, Amherst, MA 01003
}

3. NASA Goddard Space Flight Center, Code 975, Greenbelt, MD 20771

reflectivity are compared with the millimeter-wave measurements.

\section{WAKASA BAY FIELD EXPERIMENT}

Snowfall is an important component of the Earth's precipitation and hydrological cycle. Remote measurements of frozen hydrometeor properties have been limited because coincident measurements of microphysical and electromagnetic properties of snowfall have not been available. Ground-based radars have been widely used to monitor snowfall intensity, but even those measurements are difficult to relate to water equivalent of snow because of the vast diversity of snow habits, density, and size distributions. Moreover, the spatial coverage of radar networks is limited over most regions other than the U.S.A., Europe, and Japan.

Snowfall measurement from space has been suggested as a solution to overcome this limitation. If the precipitating clouds contain a sufficient density of ice water equivalent from snow crystals, graupel, or both, then depressed brightness temperatures (Tbs) at $85 \mathrm{GHz}$ is likely [1]. However, if the precipitation is more local or shallow (4 $\mathrm{km}$ or less), the $\mathrm{Tb}$ depression at $85 \mathrm{GHz}$ may not be as apparent. Interest has focused on frozen hydrometeor measurements at millimeter-wavelengths that are short enough to react with frozen hydrometeors and for which water vapor obscures the variable emission from the underlying snow covered surface. The NOAA Advanced Microwave Sounding Unit (AMSU) has been used to derive snowfall over land using millimeter-wave radiometry ([2], [3], [4], and [5]).

This study analyzes the millimeter-wave radiometric measurements of frozen hydrometeors during the field experiment that was held in Wakasa bay of Japan in January 29, 2003. The MM5 cloud simulation is employed to provide temperature and humidity profiles for the radiative transfer calculations.

Parameterizations to represent the electromagnetic scattering properties of snow at millimeter-wave frequencies are applied to the hydrometeor profiles derived by airborne radar measurements. Calculated Tbs, radar
The U.S. AMSR-E and Japanese AMSR teams implemented a field experiment for Jan/Feb 2003 over Wakasa Bay, Japan [6]. During the field experiment, the NASA P-3 aircraft carried the dual frequency precipitation radar (PR-2) operating at 14 and $35 \mathrm{GHz}$; a cloud radar operating at $94 \mathrm{GHz}$ (ACR); a passive microwave sensor (PSR) that simulates the AMSR observations; a high frequency passive Microwave Imaging Radiometer (MIR) covering from 90 to $340 \mathrm{GHz}$; and an upward looking radiometer at 21 and $37 \mathrm{GHz}$ (AMMR). The Japanese contribution to the experiment consisted of a dual-polarized ground-based radar and supporting surface observations that allow us to put the aircraft observations into the larger meteorological context.

Wakasa Bay, on the eastern end of the Sea of Japan, has fairly predictable cold air outbreaks in which cold air from the Eurasian continent blows over the relatively warm Sea of Japan. These storms generally produce rainfall near the surface, where warm boundary layer air mixes with the cold air aloft. The depth of the rain layer, however, is typically very shallow and in some cases, the snowfall reaches all the way to the surface.

There were 12 flights during this field experiment between January 14 and February 3, 2003 but only one case had heavy dry snow precipitation on January $29^{\text {th }}$, 2003. Since the dielectric constant of liquid water is much different from air and 'ice, the melting snow (air, ice, and water mixture) exhibits more complicated electromagnetic (EM) behavior than dry snow (air and ice mixture). As a first step to understand the EM scattering properties of snowfall, we therefore confine this study to dry snow retrieval only. 
Figures 1(a) and 1(b) show the IR Tb from the GMS satellite and the radar measured precipitation rate observed at 04 UTC in January 2003. It has been reported that the center of low pressure that had been just west of Hokkaido had moved northwards to the middle of Sakhalin Island and it deepened to $979 \mathrm{mb}$. Strong northwesterly flow over all of the Sea of Japan produced extensive areas of snow off the coast of Honshu and the western side of the Japanese Alps.

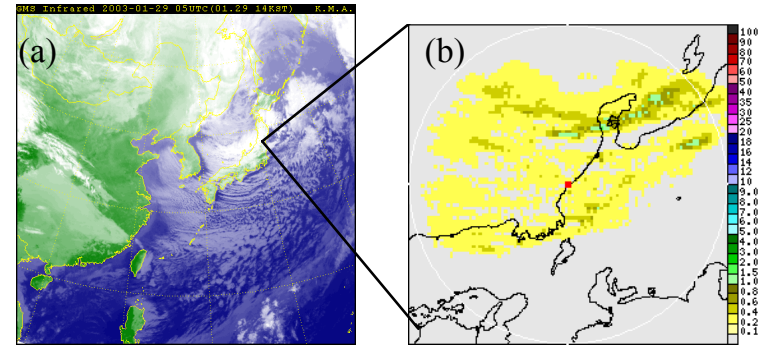

Fig. 1 (a) IR brightness temperature from the GMS satellite and (b) radar measured precipitation rate $(\mathrm{mm} / \mathrm{h})$ observed at 04 UTC in January 2003.

Figure 2 shows that air temperature near the ground measured at the Fukui airport observation site during the field experiment. The figure shows that the air temperature dropped below $0^{\circ} \mathrm{C}$ after 23 UTC January $28^{\text {th }}$ assuring dry snowfall.

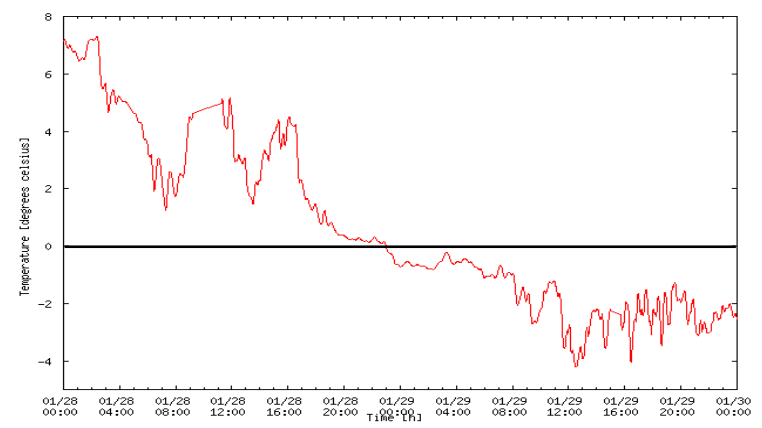

Fig.2 air temperature near the ground measured at a ground-based observation site (Fukui Airport, 36.14N, 136.22 E)

Figure 3 shows the MIR measured Tbs at 89, 150, $183 \pm 1, \pm 3$, and $\pm 7,220$, and $340 \mathrm{GHz}$ and the PR-2 measured radar reflectivity at 14 and $35 \mathrm{GHz}$, and the ACR measured radar reflectivity at $95 \mathrm{GHz}$ between 03UTC and 04UTC in January $29^{\text {th }} 2003$. The MIR Tb depression at frequencies greater than $183 \mathrm{GHz}$ is well correlated with the ACR and PR-2 radar reflectivity, overall. Brightness temperatures at $89 \mathrm{GHz}$ and $150 \mathrm{GHz}$ also show the weak depression over the precipitation region while showing contamination by the surface effect.

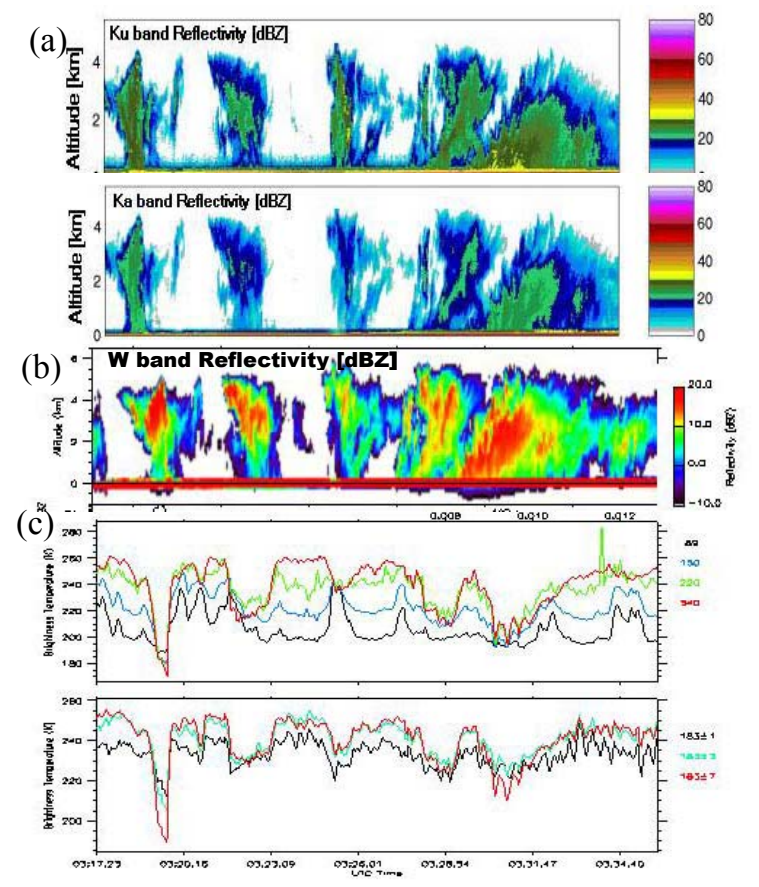

Fig.3 (a)The PR-2 measured radar reflectivity at $14 \mathrm{GHz}$ and $35 \mathrm{GHz}$ $\mathrm{GHz}$, (b) the ACR measured radar reflectivity at $95 \mathrm{GHz}$, and (c) MIR Tbs measured at $89,150,183 \pm 1, \pm 3$, and $\pm 7,220$, and $340 \mathrm{GHz}$ along nadir between 03:18UTC and 03:40UTC in January $29^{\text {th }} 2003$.

\section{SNOW MICROPHYISCS DATA}

The snow microphysics variables were measured by Kanazawa University at the ground truth site during the field experiment. Figure 4 shows snow particle size distributions (PSD) between 01-04 UTC in January $29^{\text {th }}$, 2003. The average diameters of measured snow particles range between $1 \mathrm{~mm}$ and $2 \mathrm{~mm}$ during January 28th-29th snow event.

(a)

(b)
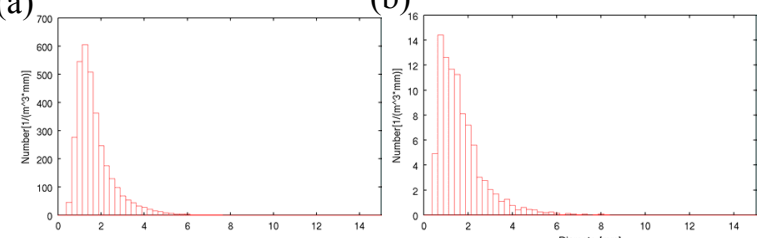

(c)
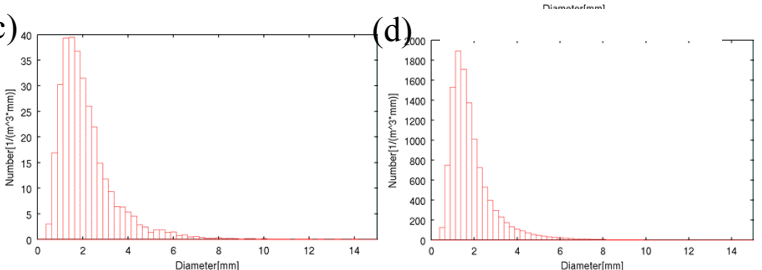

Fig. 4 The snow particle size distributions measured by Kanazawa University at the ground truth site (Fukui Airport, 36.14N, 136.22 E) during the field experiment at (a) 01 UTC, (b) 02 UTC, (c) 03 UTC, and (d) 04 UTC in January $29^{\text {th }}, 2003$.

The most popularly used PSD distribution for falling snow is the gamma distribution given by 


$$
N(D)=N_{0} D^{\mu} \exp \left(-D / D_{g}\right)
$$

where $\mathrm{D}_{\mathrm{g}}$ is one fifth of the mass-weighted mean diameter of equivalent spheres. However, we found that the gamma PSD function cannot represent the PSD observed during the field experiement because this function cannot represent the fast drop of particle numbers for sizes greater than the size where the number concentration peak occurs.

Instead the lognormal distribution given by

$$
N(D)=\frac{1}{\sqrt{2 \pi} \sigma D} \exp \left(-\left(\log \frac{D}{D_{0}}\right)^{2} /\left(2 \sigma^{2}\right)\right)
$$

was tested with optimization by matching the $1^{\text {st }}$ and $2^{\text {nd }}$ moment of size distributions. The result shows that the lognormal function represents the PSD consistent with the observations. Figure 5 compares observed PSD with the optimized lognormal PSD with $\mathrm{D}_{0}=1.6$ and $\sigma=0.5$.

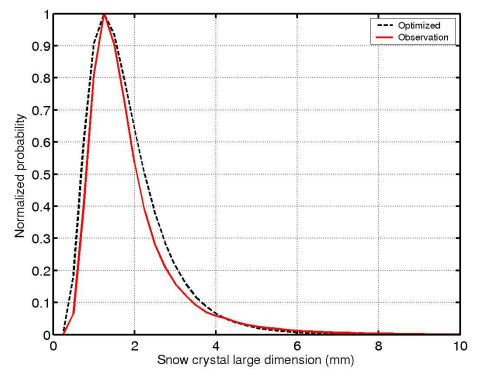

Fig. 5 Comparisons of snow particle size distributions (PSD) with the optimized lognormal PSD function.

\section{SNOWFALL RETRIEVAL METHODOLOGY}

This study seeks to derive characteristics of snow whose electromagnetic properties are consistent with microwave Tbs at several frequencies provided by the MIR sensors and the radar reflectivity measured by PR-2 and ACR radars. We have parameterized the electromagnetic scattering properties of nonspherical snow particles and preliminary results are presented in [7] and [8]. The snowfall retrieval methodology employing those parameterizations is presented in this section. Following [9], Brightness temperatures are computed from the Eddington approximation of the second kind. The radiative transfer model employs information from the Pennsylvania State University-National Center for Atmospheric Research (PSU-NCAR) fifth-generation Mesoscale Model (MM5).

Figures 6(a) and 6(b) show the MM5 forecasted $1 \mathrm{hr}$ precipitation accumulation and total precipitation (rain+snow+graupel) mixing ratio at 04 UTC, January $29^{\text {th }}$ 2003. It should be noted that the almost $100 \%$ of precipitation in Figure 6(b) is in snow. In addition, the MM5 simulated cloud top height shown in Figure 6(b) is very consistent with the ACR radar reflectivity shown in Figure 3.

In addition to ${ }^{1}$ the fractional surface snow cover (f) to adjust the surface emissivity, these MM5 profile distributions form the basis of parameters determining ${ }^{2}$ the relative humidity profile ( $\mathrm{r}$ ) and ${ }^{3}$ the snow mass profile (M) used as input for forward radiative transfer calculations with an Eddington $2^{\text {nd }}$ approximation with delta-scaling ([4],[5]). These three parameters, along with assumption of the fixed temperature profile and snow size distribution given by Eqn.(2), produce snow cloud characteristics used to generate Tbs that would be observed at the MIR frequencies using forward radiative transfer calculations. The optimal estimate of the snow parameters is derived from the best match between computed and measured Tbs at all MIR frequencies and radar reflectivity provided by PR-2 and ACR. When additional information about the snow or other aspects of the storm conditions become available, these can be included to further constrain the optimization. (a)

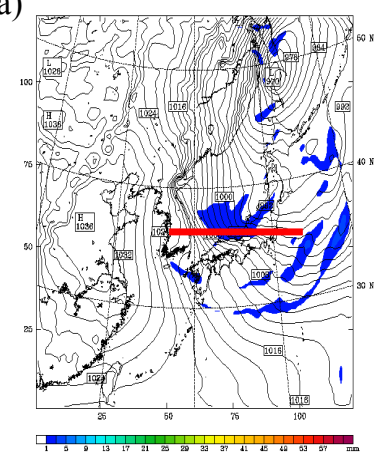

(b)

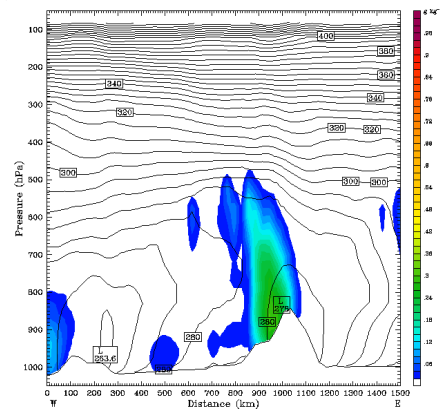

Fig.6. The MM5 forecasted (a) $1 \mathrm{hr}$ precipitation accumulation and (b) total precipitation (rain+snow+graupel) mixing ratio at 04 UTC, January $29^{\text {th }}$ 2003. The Fig6 (b) shows the cross section along the red line shown in Fig.6 (a)

The greatest challenge of this study is determining the electromagnetic properties of the wide variety of shapes and sizes of snowflakes. Comparing the Discrete-Dipole Approximation (DDA) method [10] calculated single scattering properties for nonspherical particles (hexagonal column, hexagonal disks, sector plates, planar rosette, and spatial rosette), [7] show that equal-V/A and equal-V spheres can reasonably well present the extinction efficiency while equal-V/A spheres (equal-V and equal-A spheres) show significantly smaller (larger) asymmetry factor than the DDA results. The study also found that the dielectric mixing approaches employed by [11] for a dendrite do not seem applicable to generate reasonable single scattering properties especially for complex snow flakes that contains large fraction of air due to significantly underestimated extinction efficiency and overestimated asymmetry parameters at millimeter-frequencies. The inappropriateness of applying effective medium mixing theories to irregularly shaped hydrometeors with size parameter of large structural inhomogeneities was also addressed by [12].

Although the DDA method can be used to compute the scattering characteristics of non-spherical particles, the shape of the frozen crystal habit can only be crudely or 
sometimes impossible to estimate so that a simpler parameterization is necessary.

Figure 7 shows the single scattering properties for randomly oriented hexagonal columns (left panels) and spatial rosettes (right panel) calculated by the DDA method. Three equivalent sphere approaches (equalvolume (V), equal-area (A), equal-V/A spheres) are compared. To average over the resonant peaks in the phase functions, the scattering results for 14 large dimensions ranging $0.25 \mathrm{~mm}$ to $3 \mathrm{~mm}$ are normalized using the optimized snow PSD function given by Eqn.(2). The DDA calculated the extinction cross-sections are between values calculated with the equal-V and equal-V/A spheres. All of equivalent spheres show significantly less asymmetry factor than the nonspherical particles calculated with the DDA method at frequencies greater than $140 \mathrm{GHz}$. Equal$\mathrm{V}$ and equal-A spheres overestimated backscattering crosssections while equal-V/A spheres underestimated.

\section{SUMMARY AND FUTURE WORK}

The ground based data and airborne radar/radiometer observations during the Wakasa bay field experiment were presented. It was found that a lognormal distribution represents the snow PSD during the field experiments. The MM5 cloud simulation is employed to provide temperature and humidity profiles for the radiative transfer calculations. Preliminary results for the single scattering parameterizations for nonspherical snow crystals were presented.

The parameterizations to represent the electromagnetic scattering properties of snow at millimeter-wave frequencies will be applied to the hydrometeor profiles derived by airborne radars (PR2 and ACR). Calculated Tbs will be compared with the millimeter-wave measurements provided by the MIR.
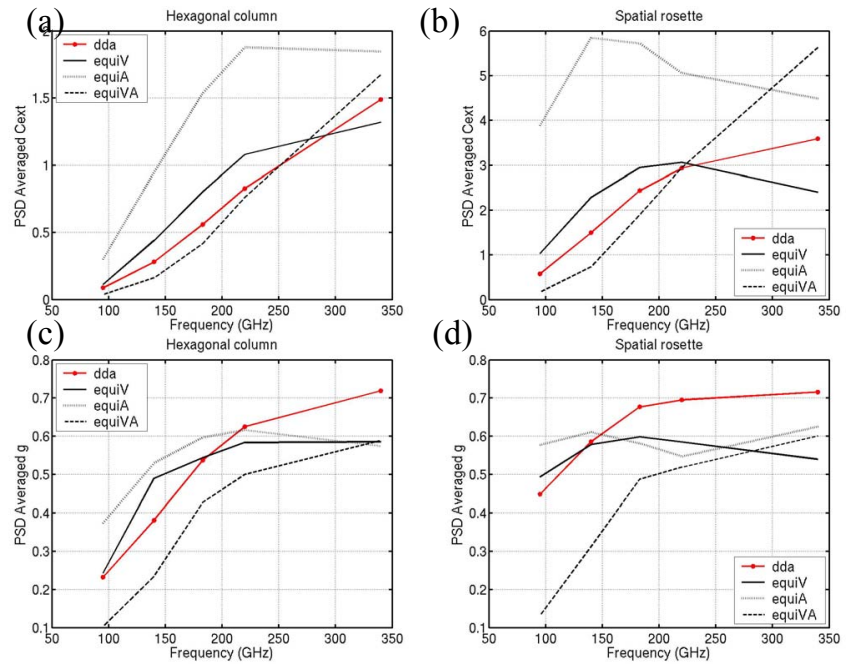

Fig. 7 Comparisons of single scattering properties calculated by the DDA method, equal-volume sphere, equal-area sphere, and equal-volume/area spheres. (a) and (b) shows extinction cross section and (c) and (d) shows the asymmetry factor.

\section{ACKNOWLEDGEMENTS}

This work has been supported by NASA Grant \#NCC-5-584, \#S-69019-G, and NAG5-9668. We thank to Drs. Tom Grenfell, Qiang Fu, Frank Evans, and Wenbo Sun for valuable discussions regarding their work on scattering characteristics of ice particles. We also thank to Dr. Bruce Draine and Piotr Flatau for providing us with the DDSCAT code and to Prof. Muramoto at the Kanazawa University for providing us ground-validation data. We are also grateful to Drs. Gail Skofronick-Jackson, Wei.-Kuo Tao, and Chung-Lin Shie at the Goddard for their support for this study. Part of the research described in this paper was performed at the Jet Propulsion Laboratory, California Institute of Technology for the AQUA/AMSR-E validation program under contract with the National Aeronautics and Space Administration. Interest in our work by Dr. Ramesh Kakar of Code Y at NASA HQ is also gratefully acknowledged.

\section{REFERENCES}

[1] Bennartz, R. and G.W. Petty, 2003: The sensitivity of microwave remote sensing observations of precipitation to ice particle size distributions. J. Appl. Meteor. 40, 345-364.

[2] Kongoli, C., P. Pellegrino, R. Ferraro, N. Grody, 2003: Identification and retrieval of snowfall over land from the Advanced Microwave Sounding Unit (AMSU) $83^{\text {rd }}$ Annual Meeting, Am. Met. Soc., 9-13-Feb., 2003, Long Beach CA.

[3] Chen,F.W. and D.H. Staelin, 2003: AIRS/AMSU/HSB precipitation estimates. IEEE Trans. On Geosci. and Remote Sensing, 41, 310-417.

[4] Kim, M.-J., G. Skofronick-Jackson, J. A. Weinman, and D.-E. Chang, 2003: Spaceborne passive microwave measurement of snowfall over land, Proceedings of the IEEE International Geosci. and Remote Sens. Symposium(IGARSS), Toulous, France, July 2125, 2003, (5), 3136-3165.

[5] Skofronick-Jackson, G., M.-J. Kim, J. A. Weinman, and D.-E. Chang, 2004: A physical model to determine snowfall over land by microwave radiometery. IEEE Trans. Geosci. Remote Sensing, Vol.42 pp.1047-1058

[6] Wilheit, T. T., C. Kummerow, R. Ferraro, R. Austin, R. Bennartz, E. Im, and T. Bell, 2002: AMSR rainfall validation implementation strategy, http://rain.atmos.colostate.edu/Wakasa

[7] Kim, M.-J., J. A. Weinman, and W. Sun, 2004a: Computation of electromagnetic characteristics of frozen hydrometeors and comparisons with millimeter-wave measurements, Proceedings of the IEEE International Geosci. and Remote Sens. Symposium(IGARSS), Anchorage, Alaska, September 20-24, 2004.

[8] Kim, M.-J. and J. A. Weinman, 2004b: Parameterizations of single scattering properties for frozen hydrometeors at millimeterwave frequencies, Proceedings of the IEEE International Geosci. and Remote Sens. Symposium(IGARSS), Anchorage, Alaska, September 20-24, 2004.

[9] Kim, M.-J., G. Skofronick-Jackson, and J. A. Weinman, 2004c: Intercomparison of millimeter wave radiation transfer models. IEEE Trans. Geosci. Remote Sensing, (in press)

[10] Drain, B. T. and P. K. Flatau, 2003: User guide for the Discrete Dipole Approximation Code DDSCAT (version 6.0) http://www.astro.princeton.edu/ draine/DDSCAT.6.0.html

[11] O’Brien, S. G. and G. H .Goedecke 1988: Scattering of millimeter waves by snow crystals and equivalent homogeneous symmetric particles, Applied Optics, 27, 2439-2444.

[12] Sihvola, A.H. 1989: Self-consistency aspects of dielectric mixing theories. IEEE Trans. on Geosci. and Remote Sens., 27, 403-415 